\section{Periapical Repair Following Endodontic Surgery: Two- and Three-Dimensional Imaging Evaluation Methods}

Érica Gouveia Jorge', Mario Tanomaru-Filho', Juliane Maria GuerreiroTanomaru', José Maurício dos Santos Nunes Reis², Rubens Spin-Neto ${ }^{3}$, Marcelo Gonçalves ${ }^{4}$

This study quantitatively assessed the periapical bone repair following endodontic surgery, using planimetric evaluation based on two- (conventional and digital intraoral radiographic images - IRs) and three-dimensional (cone beam computed tomography - CBCT) evaluation. Eleven maxillary anterior teeth (of 11 patients) with periapical bone lesions and indication for surgical endodontic treatment were selected. IRs and CBCT images were acquired before the endodontic surgery, and 48 h, 4, and 8-months after the surgery. In each period of evaluation, the area $\left(\mathrm{mm}^{2}\right)$ of the bone lesion was measured in the images, and the values for the three methods were compared. The area in the CBCT images was measured in the mesio-distal sections comprising the largest diameter of the lesion. Data were submitted to repeated measures 2-way ANOVA and t-tests with Bonferroni correction. There was significant difference between the periods of evaluation ( $p=0.002$ ) regarding the assessed periapical bone lesion area. There was no statistically significant difference between the methods of evaluation $(p=0.023)$. In the CBCT images the lesion areas were 10\% larger than those observed in the conventional IRs $\left(22.84 \mathrm{~mm}^{2}\right)$ and $15 \%$ larger than those observed in the digital IRs $\left(21.48 \mathrm{~mm}^{2}\right)$. From the baseline $\left(40.12 \mathrm{~mm}^{2}\right)$ to $4\left(20.06 \mathrm{~mm}^{2}\right)$ and 8 -months $\left(9.40 \mathrm{~mm}^{2}\right)$, reductions of 50 and $77 \%$ in the lesion area, respectively, were observed $(\mathrm{p}<0.0001)$. From 4 to 8 -months, this value was 53\%. Progressive bone repair could be seen from $48 \mathrm{~h}$ to 8 -months following endodontic surgery based on two- (conventional and digital IRs) and three-dimensional (CBCT) evaluation. CBCT images provided results similar to those assessed by means of IRs.

\author{
'Department of Restorative \\ Dentistry, Araraquara Dental \\ School, UNESP - Univ Estadual \\ Paulista, Araraquara, SP, Brazil \\ ${ }^{2}$ Department of Prosthodontics, \\ Araraquara Dental School, \\ UNESP - Univ Estadual Paulista, \\ Araraquara, SP, Brazil \\ ${ }^{3}$ Department of Dentistry \\ and Oral Radiology, Aarhus \\ University, Aarhus, Denmark \\ ${ }^{4}$ Department of Diagnosis and \\ Surgery, Araraquara Dental \\ School, UNESP - Univ Estadual \\ Paulista, Araraquara, SP, Brazil
}

Correspondence: Prof. Dr. Mario Tanomaru-Filho, Rua Humaitá, 1680, CP 331, 14801-903 Araraquara, SP, Brazil. Tel: +55-16-3301-6391. email: tanomaru@uol.com.br

\section{Introduction}

The goal of endodontic surgery is to treat those cases not fully solved by conventional endodontic treatment. Its success is usually evaluated by means of clinical and radiographic follow-up (1-3). Intraoral radiographic images (IRs) are the most used method for evaluating periapical bone repair. IRs however provides limited two-dimensional information about size, extension and localization of the periapical lesion (4). The amount of detail provided in the mesio-distal plane is acceptable, while the superimposition of anatomic structures hampers the observation of details in the buco-lingual plane (5). Bone lesions in human mandibles are detected by means of IRs only when resorption of the cortical bone occurs (6). Therefore, IRs have limitations in the diagnosis and evaluation of periapical bone repair after conventional or surgical endodontic treatment $(4,7-9)$.

The evaluation of periapical bone repair after surgical endodontic treatment by means of IRs has been previously described in literature (1-3). Tawil et al. (3) evaluated the radiographic and histological repair after endodontic surgery performed in dog teeth, and stated that better bone repair was seen by means of radiographic evaluation compared to histological evaluation. Lindeboom et al. (1) evaluated the radiographic bone repair one week, 3 months and 1 year after performing endodontic surgery, and observed $92 \%$ of complete periapical bone repair after 12 months. Schwartz-Arad et al. (2) evaluated periapical bone repair after endodontic surgery by means of IRs taken after an interval ranging from 6 to 45 months, and observed complete repair in $44.3 \%$ of the cases, incomplete repair in $21.3 \%$ and unsatisfactory repair in $34.4 \%$ of the clinical cases.

Recently, cone beam computerized tomography (CBCT), which provides three-dimensional images of dental and maxillofacial structures, started being introduced for the evaluation of periapical bone lesions, and their repair after surgical endodontic treatment (6). In the literature, there is a clear tendency of higher accuracy for periapical bone lesions detection using CBCT compared to twodimensional imaging methods $(6,10)$. Velvart et al. (4) compared the information obtained from IRs and CBCT images in detecting periapical bone lesions. Those authors diagnosed 80 lesions by means of CBCT evaluation, while only 61 were observed by means of IRs. Lofthag-Hansen et al. (8) also compared IRs and CBCT images in the diagnosis of periapical bone lesions. While observers found 42 teeth 
with periapical bone lesions based on CBCT images, IRs evaluation allowed the observation of only 32 teeth with lesions. Paula-Silva et al. (7) evaluated periapical bone lesion repair in teeth treated in one or two sessions, and verified repair in 79\% of the bone periapical lesions by means of IRs evaluation, whereas only 35\% showed repair in CBCT evaluation. Regarding the quantification of periapical bone repair following endodontic surgery based on IRs and CBCT images literature is still limited to in vitro studies (11).

The objective of this study was to quantitatively assess the periapical bone repair following endodontic surgery, using planimetric evaluation based on two- (conventional and digital IRs) and three-dimensional (CBCT) evaluation.

\section{Material and Methods}

Eleven patients referred to the Endodontic clinic of Araraquara Dental School (UNESP - Univ Estadual Paulista, Brazil) (both genders, over the age of 18 years) were selected for this study. The teeth selected were maxillary anterior single-rooted teeth, with the presence of radiographically (IR) visible periapical bone rarefaction, and the indication for surgical endodontic surgical treatment. The protocol was implemented after approval by the institutional Research $\therefore$ Ethics Committee, and all selected patients signed a consent form to be included in the study.

Before the endodontic surgery was performed, conventional and digital periapical radiographs, and CBCT of the region of interest were taken. For the conventional and digital periapical radiographs, a standardization technique was used (12). This technique consists of the use of a positioner for radiographic films, model Rinn XCP (Rinn Corp, Elgin, IL, USA), stabilized with silicone (Elite HD, Zhermack, Badia Polesine, Rovigo, Italy), placed on the incisal surfaces of the teeth to be radiographed. This procedure standardized the tooth position and angle of incidence of the radiographic beam while the radiographs were taken. After taking the radiograph, the mold was washed in running water and then immersed in a 1.0\% $\mathrm{NaOCl}$ solution for disinfection. After disinfection, the mold was stored in a recipient identified with the patient's name, and kept refrigerated for use in the subsequent periods of evaluation.

The conventional periapical radiographs were taken using Insight F-speed radiographic films (Eastman Kodak Company, Rochester, NY, USA). The unit was a GE 1000 (General Electric, Milwaukee, WI, USA) set to $90 \mathrm{kV}, 10$ $\mathrm{mA}$, with a fixed focus-film distance of $40 \mathrm{~cm}$, provided by the positioner and exposure time of $0.2 \mathrm{~s}$. After the radiograph was taken, the periapical film was automatically processed in a Dent-X 9000 film processer (Dent-X Film Processer; Dent-X Co., Elmsford, NY, USA). The digital periapical radiographs were obtained with the use of the radiographic positioner, according to the standardization described, adjusted to the $3 \times 4 \mathrm{~cm}$ sensor of the CCD Kodak RVG6000 digital system (Eastman Kodak Company), connected to a computer. The radiographic exposure factors used were the same as those described previously, except for the time of incidence of the X-rays, which was shorter $(0.08 \mathrm{~s})$. At the time each radiograph was taken, a metal sphere with a known diameter $(3.97 \mathrm{~mm})$ was used fixed on the surface of the tooth crown and on the mucosa, close to the periapical region to be evaluated. Thus, it was possible to calculate the real area of the periapical bone lesion in the IRs, compensating for its possible dimensional distortion (13).

CBCT images were acquired using a i-Cat unit (Imaging Sciences-Kavo, Hatfield, PA, USA). The CBCT unit was set at $120 \mathrm{kVp}, 5 \mathrm{~mA}$, with an examination time of 20 seconds. Recent guidelines state that for the diagnosis of periapical pathology the smallest available field-of-view should be used, and therefore, based on the characteristics of the used unit, a field-of-view of $6.0 \times 16 \mathrm{~cm}$ and a voxel size of 0.25 $\mathrm{mm}$ were selected (6). The images were reconstructed as a volume using dedicated software (i-Cat Vision, Imaging Sciences International, Hatfield, PA, USA), and theses volumes were saved as DICOM files. Later, one independent and trained evaluator evaluated those image volumes using dedicated software (OnDemand 3D 1.0.7.0295, Cybermed, Seoul, South Korea). Both IRs and CBCT images were used for the definition of the treatment plan.

After the initial imaging procedures, the endodontic surgery was performed according to the treatment plan for each case. The patients were submitted to local anesthesia using 2\% mepivacaine with epinephrine 1:100.000 (Mepiadre; DFL Indústria e Comércio S.A., Rio de Janeiro, RJ, Brazil). Surgical access was performed through incision of the soft tissues over the surgical site, followed by soft-tissues avulsion to expose the vestibular bone plate. Ostectomy was performed with surgical chisels and a spherical burr, in a straight hand piece at low speed, under constant manual irrigation with physiological solution. The surgical recess was considered adequate the moment it was possible to gain access for curettage of the periapical pathological tissue. After this, apicectomy was performed, at $3.0 \mathrm{~mm}$ from the apical root portion, in a direction perpendicular to the long axis of the tooth, by means of a Zekrya cutter (Dentsply/Maillefer, Ballaigues, Switzerland) at high speed. The retropreparations were made with a depth of $3.0 \mathrm{~mm}$, using 6.1107-6 ultrasonic diamond tips (CVD;-Vale, São José dos Campos, SP, Brazil) with the UA-4 adaptor (CVD-Vale) coupled to the Piezon miniMaster ultrasound appliance (EMS, LeSentier, Switzerland) at 50\% power. During the apicectomies and retropreparations, abundant irrigation was performed with an isotonic sodium chloride solution. 
The retrograde fillings were performed with MTA (Angelus, Londrina, PR, Brazil). After 7 days, patients were scheduled for post-operative evaluation and suture removal.

Each patient was then scheduled to have IRs (Figs. 1 and 2) and CBCT images (Fig. 3) acquired after the periods of 48 h, 4 and 8 months. At each return visit, the previously fabricated silicone mold was re-positioned together with the positioner. After taking the image, the mold was washed, disinfected and stored under refrigeration, as previously described.

\section{IRs Assessment}

The conventional IRs were digitized (resolution of 300 dpi), using a Nikon D7000 digital reflex camera (Nikon Inc., Tokyo, Japan), coupled to a $105 \mathrm{~mm}$ Nikon micro lens with
VRII image stabilization system, in a standardized focal distance. For this purpose, a stative device was used, making it possible for all the images to be digitized on the same manner. The images were filed in RAW format, without compression, and imported into the Adobe Photoshop CS6 program (Adobe Systems Inc., San Jose, California, USA). Images were then converted to gray scale and had the histogram standardized, and saved as uncompressed TIF files. Digital IRs were originally provided as uncompressed TIF files. All generated images were anonymized and randomized at the patient level, in order to blind the evaluator with respect to treatment group. ImageJ software ( $\mathrm{NIH}$, Bethesda, MD, USA) was used to delimit the outline of the bone periapical lesions. For this purpose, after the images were imported into ImageJ, the software was
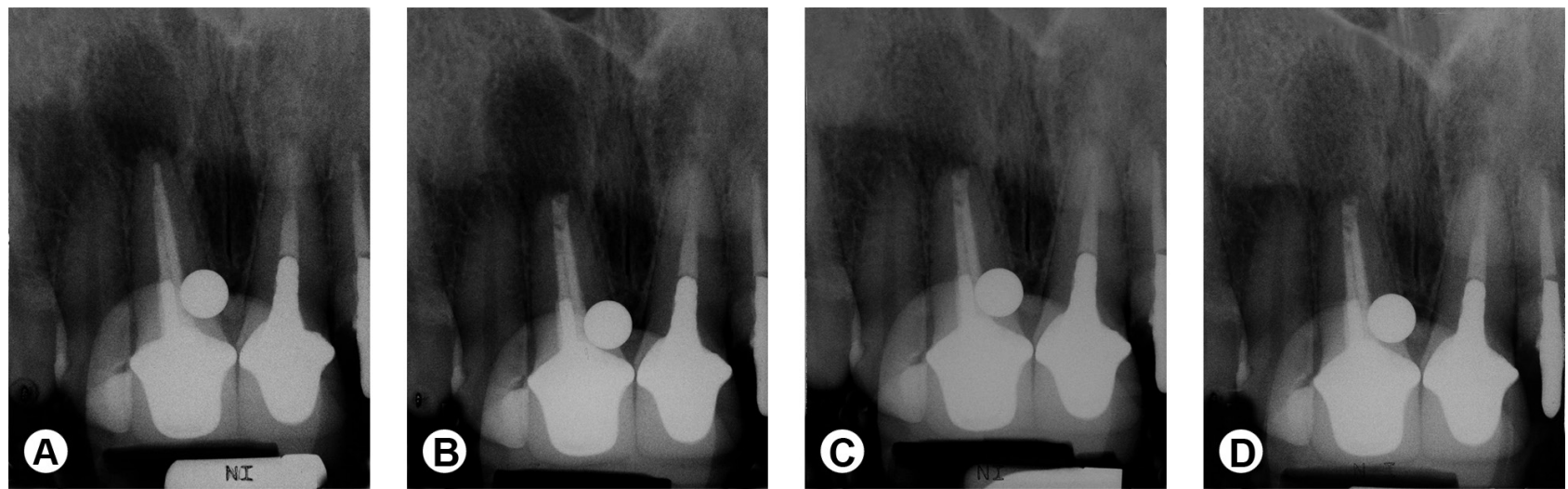

Figure 1. Conventional intraoral radographic images taken before (A), and $48 \mathrm{~h}(\mathrm{~B}), 4$ months (C) and 8 months (D) after endodontic surgery.
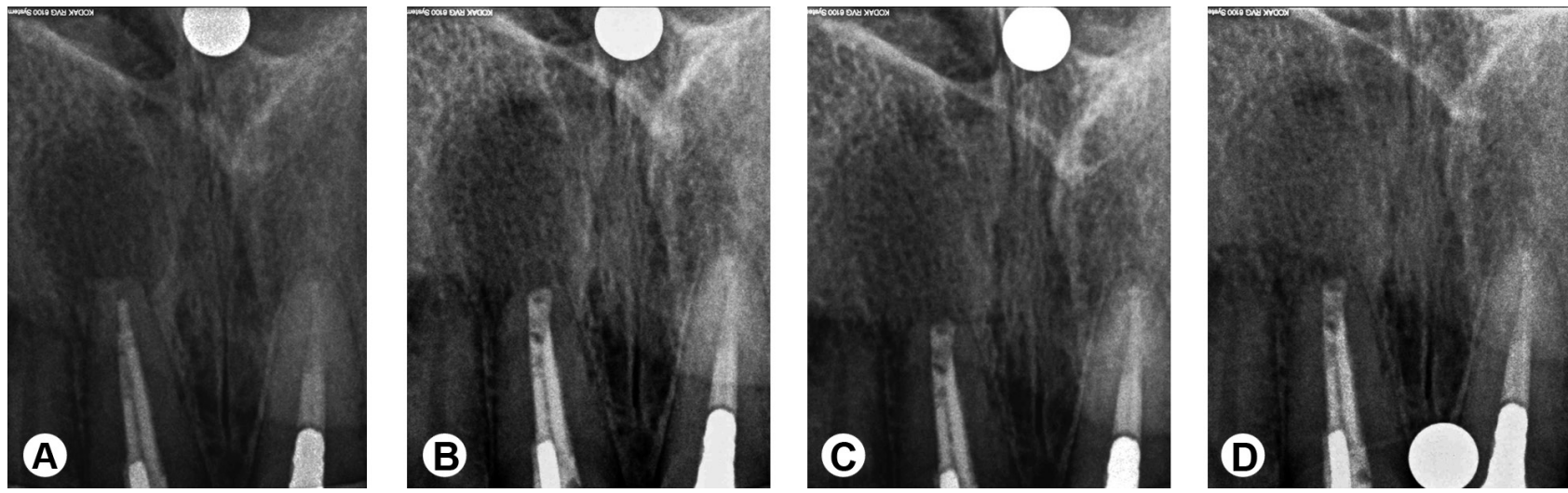

Figure 2. Digital intraoral radographic images taken before (A), and 48 h (B), 4 months (C) and 8 months (D) after endodontic surgery.
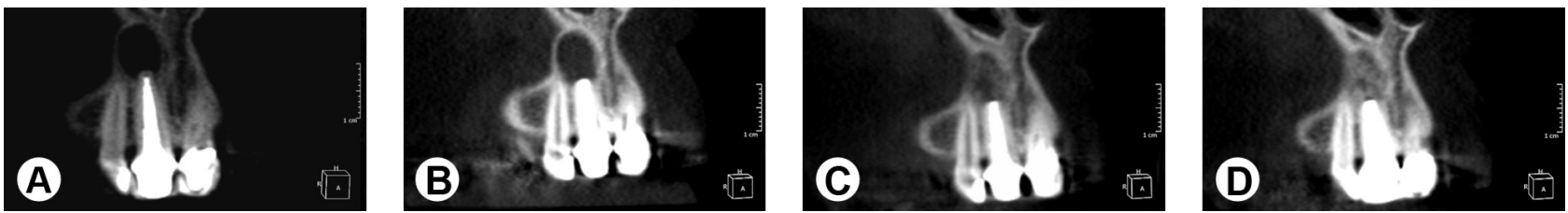

Figure 3. CBCT images acquired before (A), and $48 \mathrm{~h}(\mathrm{~B}), 4$ months (C) and 8 months (D) after endodontic surgery. 
calibrated using a known scale in millimeters (diameter of the metal sphere $=3.97 \mathrm{~mm}$ ). In the sequence the lesion areas were delimited with the computer mouse, and the values originally measured in pixels were automatically converted into square millimeters $\left(\mathrm{mm}^{2}\right)$. Three previously trained evaluators made the evaluations (two endodontists and one radiologist). The areas assessed in all periods of evaluation were saved in a table for further comparison with the values assessed in the CBCT images.

\section{CBCT Assessment}

Using dedicated software (OnDemand 3D 1.0.7.0295, Cybermed, Seoul, South Korea), for each selected tooth, a central mesiodistal section $0.5 \mathrm{~mm}$ thick was selected. The exhibition contrast of the image was adjusted, and the center level ( $\mathrm{L}$ ) and band-width (W) were set according the suggestions in the software $(W=3086$ and $L=667)$. For every CBCT section, one TIF (tagged image file) image was generated. The images had a resolution of $96 \mathrm{dpi}$ matching unit resolution and therefore avoiding any distortion. They contained a ruler, which allowed the setting of the linear scale of each image. All generated images were rendered anonymous and randomized at the patient level, in order to blind the evaluator with respect to treatment group. In the sequence the areas of the periapical bone lesions were assessed in the same manner as it was performed for the IRs.

Table 1. Results of the t-test for the isolated factor Method of Evaluation, with confidence intervals adjusted by Bonferroni (C198.3), and values of correlation among the methods

\begin{tabular}{lcccc}
\hline Technique & $\begin{array}{c}\text { Difference among } \\
\text { groups (C198.3) }\end{array}$ & $\begin{array}{c}\mathrm{p} \\
\text { value }\end{array}$ & Correlation & $\begin{array}{c}\mathrm{p} \\
\text { value }\end{array}$ \\
\hline $\begin{array}{l}\text { Conventional X } \\
\text { digital radiography }\end{array}$ & $\begin{array}{c}1.36(-0.522 \\
\text { to } 3.241)^{\mathrm{A}}\end{array}$ & 0.078 & 0.978 & $<0.0001$ \\
$\begin{array}{l}\text { Conventional } \\
\text { radiography X CBCT }\end{array}$ & $\begin{array}{c}-2.41(-7.653 \\
\text { to } 2.841)^{\mathrm{A}}\end{array}$ & 0.257 & 0.833 & $<0.0001$ \\
$\begin{array}{l}\text { Digital radiography } \\
\text { X CBCT }\end{array}$ & $\begin{array}{c}-3.77(-7.706 \\
\text { to } 0.174)^{\mathrm{A}}\end{array}$ & 0.022 & 0.904 & $<0.0001$ \\
\hline
\end{tabular}

Equal letters indicate statistically similar mean values among each other $(p \geq 0.0167)$.

Table 2. Results of the t-test for the isolated factor Period of Evaluation, with confidence intervals adjusted by Bonferroni (C198.3), and values of correlation among the periods

\begin{tabular}{lcccc}
\hline Period & $\begin{array}{c}\text { Difference among } \\
\text { groups (C198.3) }\end{array}$ & $\begin{array}{c}\mathrm{p} \\
\text { value }\end{array}$ & Correlation & $\begin{array}{c}\mathrm{p} \\
\text { value }\end{array}$ \\
\hline $\begin{array}{l}\text { Initial }(48 \mathrm{~h}) \\
\text { x 4 months }\end{array}$ & $\begin{array}{c}20.06(12.086 \\
\text { to } 28.033)^{\mathrm{A}}\end{array}$ & $<0.0001$ & 0.678 & $<0.0001$ \\
$\begin{array}{l}\text { Initial }(48 \mathrm{~h}) \\
\text { x 8 months }\end{array}$ & $\begin{array}{c}30.72(21.041 \\
\text { to } 40.394)^{\mathrm{B}}\end{array}$ & $<0.0001$ & 0.421 & 0.015 \\
4 months $\mathrm{n}$ & $\begin{array}{c}10.66(7.672 \\
\text { to } 13.644)^{\mathrm{C}}\end{array}$ & $<0.0001$ & 0.882 & $<0.0001$ \\
8 months & & & & \\
\hline
\end{tabular}

Different letters indicate mean values that differ statistically among them $(p \geq 0.0167)$.

\section{Data Analysis}

The areas $\left(\mathrm{mm}^{2}\right)$ assessed in the IRs and CBCT images were submitted to the repeated measures 2-way Analysis of Variance (2-way ANOVA), with a level of significance of $5.0 \%$, using dedicated software (SPSS 20, IBM Corporation, Armonk, NY, USA). This analysis was performed in an attempt to detect the influence of the evaluation method (IRs versus CBCT) and period (48 h, 4, and 8 months), as well as their interactions in bone repair. Later, paired t-tests adjusted by Bonferroni were applied to quantify the difference between two selected methods.

\section{Results}

A significant effect was observed for the isolated factors Period of evaluation ( $\mathrm{p}=0.002$ ) and Method of evaluation $(p=0.023)$, but the interaction between them was not significant $(p=0.763)$. The $t$-tests were used to compare the means of paired samples, at a Bonferroni's adjusted level of significance ( $\alpha=0.0167)$. The results of the t-test results for the factors Method and Period of Evaluation, as well as the correlation coefficients among the groups, are shown in Tables 1 and 2, respectively.

In Table 1, it is verified that there was no difference in the values of the periapical lesion area measured by the conventional radiography $\left(22.84 \mathrm{~mm}^{2} \pm 20.78\right)$, digital radiography $\left(21.48 \mathrm{~mm}^{2} \pm 20.32\right)$, and the CBCT images $\left(25.25 \mathrm{~mm}^{2} \pm 20.68\right)$. High correlation coefficients were observed among the methods $(p<0.0001)$, suggesting the possibility of using one method to estimate the others, as well as the reliability among the techniques. A descriptive evaluation demonstrated that $\mathrm{CBCT}$ images provided results approximately 10\% larger compared to conventional radiographies and 15\% larger than those of the digital radiographies. Between the IRs (conventional versus digital), an approximate difference of $6 \%$ was detected.

Table 2 shows that the mean assessed periapical lesion areas differed regressively with the period of analysis $(p<0.0001)$. The largest areas were

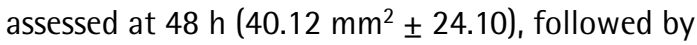
$4\left(20.06 \mathrm{~mm}^{2} \pm 12.17\right)$ and 8 months $\left(9.40 \mathrm{~mm}^{2} \pm\right.$ 7.04), respectively. Moderate to high correlation values were found when comparing $48 \mathrm{~h}$ to 4 months periods, and 4 to 8 months $(\mathrm{p}<0.0001)$. A significant $(p=0.0150)$ but moderate correlation was seen when comparing $48 \mathrm{~h}$ and 8 months. Descriptive evaluation demonstrates a decrease of approximately $50 \%$ in the areas assessed in the 48 $\mathrm{h}$ images compared to 4 months of evaluation (from 40.12 to $20.06 \mathrm{~mm}^{2}$ ). After 8 months, a decrease of 
approximately 77\% was observed compared to $48 \mathrm{~h}$ (from 40.12 to $9.40 \mathrm{~mm}^{2}$, on average). Between 4 and 8 months an area reduction of approximately 53\% was seen (from 20.06 to $9.40 \mathrm{~mm}^{2}$ ). In spite of the progressive repair observed with the evolution of the post-surgical period, radiolucent areas were still detected after 8 months of follow-up, for all tested evaluation methods.

\section{Discussion}

Several parameters influence the radiographic evaluation of periapical bone lesions, such as the cortical bone thickness, the plane of incidence of the $x$-ray beams, the composition of the mineralized tissues, the localization of the lesion, and the radiographic processing (12). It is well known that two-dimensional radiographic examination methods present limitations in the detection of periapical lesions $(7,14)$. Previous comparisons between the detection accuracy of periapical lesions by means of IRs or CBCT images has been previously reported in literature, but not focusing on the repair of the periapical lesions after surgery $(6,14-19)$. The evaluation of bone repair after endodontic surgery, using two- and three-dimensional imaging methods may help determine if and how CBCT images should be used for that purpose.

Although CBCT provides a lower radiation dose to the patient compared to traditional medical CT units (17), the values are still high when compared to the IRs traditionally used for this task (20). In this way CBCT is not advocated as the standard method for diagnosing or repair evaluation of periapical bone lesions in the current guidelines (21). High-resolution and small field-of-view CBCT images are recommended only when the conventional two-dimensional radiographic methods provide insufficient diagnostic information $(20,21)$. However, the real clinical impact of the additional information provided by CBCT images remains undetermined (6). Providing a reproducible and standardized method to quantify periapical bone lesion healing is an important step in order for that clinical question to be properly answered.

In the present study, conventional IRs were digitized for measuring the periapical lesion areas according to the method used by Peretz et al. (22). These images, together with the digital IRs were compared to $\mathrm{CBCT}$, acquired with a $0.25 \mathrm{~mm}$ resolution, according to Zapata et al. (23). The present study shows that conventional and digital IRs provided similar results regarding periapical bone repair after endodontic surgery. This agrees with the findings of other authors $(14,24)$, who observed similar values between these techniques as regards the capacity to quantifying the size of periapical bone lesions.

Similar areas were also assessed comparing conventional and digital IRs to $\mathrm{CBCT}$ images regarding the repair after endodontic surgery. CBCT has previously demonstrated greater capacity for the detection of periapical bone alterations when compared to IRs $(4,7,8,14)$. However, the similar results found for IRs and CBCT in the present study may be related to the removal of the cortical bone plate of the alveolar ridge during the surgery, eliminating one of the factors, which push down the quality of IRs. Thus, cortical bone removal may have favored conventional and digital IRs in the evaluation of periapical bone repair in a period up to 8 months of evaluation. Using an animal-based study model, Paula-Silva et al. (7) observed significant differences between CBCTs and conventional IRs during the evaluation of periapical bone repair in dog teeth six months after non-surgical endodontic treatment (in which the removal of the cortical bone wall was not realized). The present results are in agreement with those of Balasundaram et al. (15), who compared conventional IRs and CBCT images in determining the size of periapical bone lesions, and found no differences between the two diagnostic techniques, when the measurements are made by means of adequately calibrated evaluators and well standardized methods. Another important factor that may have contributed to the present results is that the central sections of the CBCT volume, in which the greatest lesion diameter was seen, were selected for measuring the areas. The tendency to larger areas assessed in CBCT images compared to the IRs is probably related to that fact.

Progressive periapical bone repair was observed among the periods of evaluation, irrespective of the used diagnostic method. Although this progression in bone repair was already expected, remaining periapical bone rarefaction could still be seen after 8 months follow-up, suggesting that longer periods of evaluation are necessary before the success of the treatment can be properly evaluated. It is also important to point out that even successfully healed periapical lesions can still be recognized as active lesions. Molven et al. (25) reported that periapical lesions may also be repaired with fibrous tissue, in addition to mineralized bone tissue after surgical procedures, and this could lead to misinterpretation of the radiographic findings. Irrespective of the diagnostic method used, periapical repair of approximately $77 \%$ was observed by means of radiographic evaluation after 8 months. The fact that none of the patients was symptomatic after that period suggests that the assessed value is a good indicative of success. Yet, studies with a longer follow-up period, focusing specially on the cases of unsuccessful healing (detected by means of clinical evaluation) would be necessary to provide reliable thresholds of what should be considered as a cut-off value to define successful periapical healing. This agrees with the most recent guidelines for the use of CBCT images in Dentistry, which address the 
fact the current evidence suggests that high resolution CBCT may have higher sensitivity for detecting periapical bone lesions than IRs (20). These guidelines also emphase that the results should be interpreted with caution, since in practice clinical signs and symptoms add significantly to the diagnostic process and radiological evidence is not always of critical importance (20).

In the present study a progressive periapical bone repair from $48 \mathrm{~h}$ to 8 months following endodontic surgery could be seen based on two- (conventional and digital IRs) and three-dimensional (CBCT) evaluation. CBCT images provided results similar to those assessed by means of IRs.

\section{Resumo}

Este estudo avaliou quantitativamente a reparação óssea periapical após cirurgia parendodôntica, utilizando avaliação planimétrica bidimensional (imagens convencionais e digitais intraorais radiográficas-IRs) e tridimensional (CBCT). Onze dentes anteriores da maxila (de 11 pacientes) com lesões ósseas periapicais e indicação de tratamento endodôntico cirúrgico foram selecionados. IRs e imagens tomográficas foram obtidas antes da cirurgia parendodôntica, e 48 h, 4 e 8 meses após a cirurgia. Para cada periodo, a área $\left(\mathrm{mm}^{2}\right)$ de rarefação óssea foi mensurada, e os valores para os três métodos comparados. A área nas imagens de CBCT foi mensurada nas seções mésio-distal, compreendendo o maior diâmetro da lesão. Os dados foram submetidos à análise de variância de medidas repetidas a dois critérios e teste T com correção de Bonferroni. Houve diferença significativa ¿ entre os períodos de avaliação $(p=0,002)$ em relação à área de lesão óssea ¿ periapical mensurada. Não houve diferença significativa entre os métodos de avaliação $(p=0,023)$. Nas imagens tomográficas as áreas das lesões foram $10 \%$ maiores do que as observados nas IRs convencionais $(22,84$ ن. $\left.\mathrm{mm}^{2}\right)$ e $15 \%$ maior do que àquelas das digitais $\left(21,48 \mathrm{~mm}^{2}\right)$. A partir dos valores baseline $\left(40,12 \mathrm{~mm}^{2}\right)$ a $4\left(20,06 \mathrm{~mm}^{2}\right)$ e 8 meses $\left(9,40 \mathrm{~mm}^{2}\right)$, foram observadas reduções de 50 e $77 \%$, respectivamente, na área das lesões $(p<0,0001)$. De 4 a 8 meses, esse valor foi de $53 \%$. Entre o periodo de $48 \mathrm{~h}$ a oito meses após as cirurgias parendodônticas foram observadas reparações ósseas progressivas nas avaliações bidimensionais (IRs convencional e digital) e tridimensional (CBCT). A CBCT produziu resultados semelhantes aqueles avaliados por meio das IRs.

\section{References}

1. Lindeboom JA, Frenken JW, Kroon FH, van den Akker HP. A comparative prospective randomized clinical study of MTA and IRM as root-end filling materials in single-rooted teeth in endodontic surgery. Oral Surg Oral Med Oral Pathol Oral Radiol Endod 2005;100:495-500.

2. Schwartz-Arad D, Yarom N, Lustig JP, Kaffe I. A retrospective radiographic study of root-end surgery with amalgam and intermediate restorative material. Oral Surg Oral Med Oral Pathol Oral Radiol Endod 2003:96:472-477.

3. Tawil PZ, Trope M, Curran AE, Caplan DJ, Kirakozova A, Duggan DJ, et al.. Periapical microsurgery: an in vivo evaluation of endodontic root-end filling materials. J Endod 2009;35:357-362.

4. Velvart $P$, Hecker $H$, Tillinger $G$. Detection of the apical lesion and mandibular canal in conventional radiography and computed tomography. Oral Surg Oral Med Oral Pathol Oral Radiol Endod 2001;92:682-688.

5. Bender IB. Factors influencing the radiographic appearance of bony lesions. J Endod 1997;23:5-14.

6. Petersson A, Axelsson S, Davidson T, Frisk F, Hakeberg M, Kvist T, et al.. Radiological diagnosis of periapical bone tissue lesions in endodontics: a systematic review. Int Endod J 2012;45:783-801.

7. Paula-Silva FW, Santamaria M Jr, Leonardo MR, Consolaro A, Silva LA. Cone-beam computerized tomographic, radiographic, and histologic evaluation of periapical repair in dogs' post-endodontic treatment. Oral Surg Oral Med Oral Pathol Oral Radiol Endod 2009;10:796-805.

8. Lofthag-Hansen S, Huumonen S, Grondahl K, Grondahl HG. Limited cone-beam CT and intraoral radiography for the diagnosis of periapical pathology. Oral Surg Oral Med Oral Pathol Oral Radiol Endod 2007;103:114-119.

9. Tanomaru-Filho M, Jorge EG, Duarte MA, Goncalves M, GuerreiroTanomaru JM. Comparative radiographic and histological analyses of periapical lesion development. Oral Surg Oral Med Oral Pathol Oral Radiol Endod 2009;107:442-447.

10. Durack $\mathrm{C}$, Patel $\mathrm{S}$. Cone beam computed tomography in endodontics. Braz Dent J 2012;23:179-191.

11. Esposito SA, Huybrechts B, Slagmolen P, Cotti E, Coucke W, Pauwels R, et al.. A novel method to estimate the volume of bone defects using conebeam computed tomography: an in vitro study. J Endod 2013;39:11111115.

12. Carvalho FB, Gonçalves M, Tanomaru-Filho M. Evaluation of chronic periapical lesions by digital subtraction radiography by using Adobe Photoshop CS: a technical report. J Endod 2007;33:493-497.

13. Souza EM, Bretas RT, Cenci MS, Maia-Filho EM, Bonetti-Filho I. Periapical radiographs overestimate root canal wall thickness during post space preparation. Int Endod J 2008;41:658-663.

14. Ozen T, Kamburoglu K, Cebeci AR, Yüksel SP, Paksoy CS. Interpretation of chemically created periapical lesions using 2 different dental conebeam computerized tomography units, an intraoral digital sensor, and conventional film. Oral Surg Oral Med Oral Pathol Oral Radiol Endod 2009; 107:426-432.

15. Balasundaram $A$, Shah $P$, Hoen MM, Wheater MA, Bringas JS, Gartner $A$ et al. Comparison of cone-beam computed tomography and periapical radiography in predicting treatment decision for periapical lesions: a clinical study. Int J Dent 2012, 920815.

16. Jorge EG, Tanomaru-Filho M, Gonçalves M, Tanomaru JMG. Detection of periapical lesion development by conventional radiography or computed tomography. Oral Surg Oral Med Oral Pathol Oral Radiol Endod 2008;106:e56-e61.

17. Ngan DC, Kharbanda OP, Geenty JP, Darendeliler MA. Comparison of radiation levels from computed tomography and conventional dental radiographs. Aust Orthod J 2003;19:67-75.

18. Estrela $C$, Holland R, Estrela $C R$, Alencar AH, Sousa-Neto MD, Pécora JD. Characterization of successful root canal treatment. Braz Dent J 2014;25:3-11.

19. Estrela $C$, Bueno MR, Porto OC, Rodrigues CD, Pécora JD. Influence of intracanal post on apical periodontitis identified by cone-beam computed tomography. Braz Dent J 2009;20:370-375.

20. SEDENTEXCT Project. Radiation protection n. 172: Cone Beam CT for dental and maxillofacial radiology. 2012; European Commission Directorate-General for Energy: Luxembourg.

21. AAE \& AAOMR. Use of cone-beam computed tomography in endodontics Joint Position Statement of the American Association of Endodontists and the American Academy of Oral and Maxillofacial Radiology. Oral Surg Oral Med Oral Pathol Oral Radiol Endod 2011;111:234-237.

22. Peretz B, Kaffe I, Amir E. Digital images obtained with a digital camera are not associated with a loss of critical information - a preliminary study. Br Dental J 2009;206:E9; discussion 268-269.

23. Zapata RO, Bramante CM, Duarte MH, Ramos Fernandes LM, Camargo EJ, Moraes IG, et al. The influence of cone-beam computedtomography and periapical radiographic evaluation on the assessment of periapical bone destruction in dog's teeth. Oral Surg Oral Med Oral Pathol Oral Radiol Endod 2001;112:272-279.

24. Stavropoulos A, Wenzel A. Accuracy of cone beam dental CT, intraoral digital and conventional film radiography for the detection of periapical lesions. An ex vivo study in pig jaws. Clin Oral Inv 2007;11:101-106.

25. Molven 0, Halse A, Grung B. Incomplete healing (scar tissue) after periapical surgery-radiographic findings 8 to 12 years after treatment. J Endod 1996;22:264-268. 